\title{
Behaviour of steel and composite beam-column joints subjected to quasi-static and impact loads
}

\author{
K. Chen ${ }^{a}$, K. H. Tan ${ }^{\text {a* }}$ \\ ${ }^{a}$ Nanyang Technological University, Singapore \\ *corresponding author, e-mail address: ckhtan@ntu.edu.sg
}

\begin{abstract}
The behaviour of steel and composite beam-column joints was investigated in this paper. A test programme on typical beam-column joints subjected to quasi-static and impact loads was presented. A comparison of different connections was conducted and composite slab effect was investigated. Based on the test results, a component-based modelling approach was proposed and validated. Basic nonlinear springs of beam-column joint models were developed. Mechanical properties of the nonlinear springs were defined based on either current design codes or models proposed by previous researchers. Good agreement with test results was achieved by the component-based models.
\end{abstract}

Keywords: Beam-column joint; impact load; column removal; progressive collpase

\section{Introduction}

Beam-column joints play an import role in the robustness of building structures when structures are subjected to progressive collapse scenarios. Currently, many tests have been conducted on both fin plate (FP) [1-5] and welded unreinforced flange with bolted web (WUF-B) [6-12] connections. However, most of the previous tests focused on the behaviour of bare steel joints. The potential benefit of composite slab has not been fully investigated so far. Moreover, progressive collapse is a dynamic process in nature. Therefore, it is urgent to study the dynamic behaviour of beam-column joints. To meet the technical gaps, a test programme and a component-based modelling approach for beam-column joints subjected to quasi-static and impact loads are presented in this paper.

\section{Experimental study}

\subsection{Test programme}

A total of twelve half-scale beam-column joints with FP and WUF-B connections were designed based on Eurocode 3 Part 1-1, Eurocode 4 Part 1-1 [13, 14], AISC 360 [15] and AISC 325 [16] and their detailed information is provided in Table 1. Recommendations in
FEMA 350 [17] were also considered. To identify each specimen, they are named based on the concrete slab thickness and connection detailing, such as C75 stands for $75 \mathrm{~mm}$ thick composite slab, FP for fin plate connection, W for WUF-B connection, $\mathrm{M}$ for the middle joint while $\mathrm{S}$ for the side joint, $\mathrm{R}$ for reduced number of shear studs, slot for slotted holes and rbs for reduced beam section. For instance, specimen C75FP-Mslot was a middle joint with $75 \mathrm{~mm}$ thick composite slab, fin plate connection and slotted bolt holes were used in the fin plates. For all the specimens, Grade S355 universal beams (UB $203 \times 133 \times 30$ ) and columns (UC $203 \times 133 \times 71$ ) were used and connected by Grade S275 fin plates and Grade 10.9 M20 bolts. A pretorque of $280 \mathrm{kNm}$ was applied to the bolts.

Eleven half-scale beam-column joints with FP and WUF-B connections were tested under impact loads and the details are shown in Table 2. The nomenclature is as follows: $\mathrm{C}$ stands for composite slab, FP for fin plate, W for WUF-B, $\mathrm{M}$ for mass, and $\mathrm{H}$ for height. For instance, specimen C75FP-M530H3 had a $75 \mathrm{~mm}$ thick composite slab and fin plate connections. It was subjected to an impact load from a $530 \mathrm{~kg}$ mass hammer dropping from $3 \mathrm{~m}$ height. 
Table 1. Summary of quasi-static test specimens.

\begin{tabular}{|c|c|c|c|}
\hline ID & $\begin{array}{l}\text { Slab } \\
(\mathrm{mm})\end{array}$ & Joint location & Shear studs \\
\hline FP-static & l & I & l \\
\hline C75FP-M & 75 & Middle & $\begin{array}{c}2 \text { rows@ } \\
90 \text { mm }\end{array}$ \\
\hline C75FP-S & 75 & Side & $\begin{array}{c}2 \text { rows@ } \\
90 \mathrm{~mm}\end{array}$ \\
\hline C100FP-M & 100 & Middle & $\begin{array}{c}2 \text { rows } 9 \\
90 \mathrm{~mm}\end{array}$ \\
\hline C75FP-MR & 75 & Middle & $\begin{array}{l}1 \text { row @ } \\
180 \text { mm }\end{array}$ \\
\hline C75FP-Mslot & 75 & Middle & $\begin{array}{c}2 \text { rows@ } \\
90 \mathrm{~mm}\end{array}$ \\
\hline W-static & / & / & I \\
\hline C75W-M & 75 & Middle & $\begin{array}{c}2 \text { rows@ } \\
90 \mathrm{~mm}\end{array}$ \\
\hline $\mathrm{C} 75 \mathrm{~W}-\mathrm{S}$ & 75 & Side & $\begin{array}{c}2 \text { rows@ } \\
90 \text { mm }\end{array}$ \\
\hline C100W-M & 100 & Middle & $\begin{array}{c}2 \text { rows@ } \\
90 \text { mm }\end{array}$ \\
\hline C75W-MR & 75 & Middle & $\begin{array}{l}1 \text { row@ } \\
180 \text { mm }\end{array}$ \\
\hline C75W-Mrbs & 75 & Middle & $\begin{array}{c}2 \text { rows@ } \\
90 \text { mm }\end{array}$ \\
\hline
\end{tabular}

Nomenclature: C - Composite; FP - Fin plate; W - WUFB; M - Middle joint; S - Side joint; R - Reduced number of shear studs; slot - slotted holes; rbs - reduced beam section

Table 2. Summary of impact test specimens.

\begin{tabular}{|c|c|c|c|}
\hline ID & $\begin{array}{c}\text { Drop- } \\
\text { weight } \\
(\mathrm{kg})\end{array}$ & $\begin{array}{l}\text { Height } \\
\text { (m) }\end{array}$ & $\begin{array}{c}\text { Impact } \\
\text { velocity } \\
(\mathrm{m} / \mathrm{s})\end{array}$ \\
\hline FP6-M530H3 & 530 & 3.015 & 7.389 \\
\hline FP10-M530H3 & 530 & 3.015 & 7.305 \\
\hline C75FP-M530H3 & 530 & 3 & 7.518 \\
\hline $\begin{array}{c}\text { C75FP- } \\
\text { M770H1.425 }\end{array}$ & 770 & 1.425 & 5.020 \\
\hline C75FP-M530H3-S & 530 & 2.994 & 7.388 \\
\hline C100FP-M530H3 & 530 & 2.995 & 7.469 \\
\hline W-M830H3 & 830 & 2.993 & 7.235 \\
\hline C75W-M770H3 & 770 & 2.998 & 7.619 \\
\hline C75W-M770H2 & 770 & 2.005 & 6.230 \\
\hline C75W-M770H3-S & 770 & 2.997 & 7.357 \\
\hline C100W-M770H3 & 770 & 2.996 & 7.357 \\
\hline
\end{tabular}

Nomenclature: C - Composite; FP - Fin plate; M Mass, kg; H - Drop-height, m; S - Side joint

Based on standard $150 \mathrm{~mm}$ diameter by 300 $\mathrm{mm}$ length cylinder tests, concrete compressive strength and the corresponding standard derivation are shown in Table 3.
Table 3. Concrete material properties.

\begin{tabular}{ccc}
\hline Test series & $\begin{array}{c}\text { Compressive } \\
\text { strength (MPa) }\end{array}$ & $\begin{array}{c}\text { Standard } \\
\text { derivation } \\
(\mathrm{MPa})\end{array}$ \\
\hline FP quasi-static & 36.7 & 2.8 \\
WUF-B quasi-static & 37.4 & 1.4 \\
FP impact & 37.0 & 3.6 \\
WUF-B impact & 50.6 & 5.4 \\
\hline A hydraulic actuator with & displacemen
\end{tabular}

A hydraulic actuator with displacement control at $6 \mathrm{~mm} / \mathrm{min}$ was employed to apply a quasi-static load to beam-column specimens as shown in Fig. 1. The actuator has a capacity of $500 \mathrm{kN}$. The quasi-static load was monotonically applied on the middle column joint for a vertical 'push-down' test to find the maximum capacity. On the left side, a strong A-frame was used to simulate a pinned support while on the right side the specimens were connected to a pinned support reacting against a strong wall. The two pinned supports were used to simulate the inflexion points located roughly at the one-third span of each beam after the middle column was removed. The beam span was $3668 \mathrm{~mm}$, smaller than a typical full-scale steel frame, to fit within the limited space in the laboratory. The test setup was validated by tests conducted previously by Yang and Tan [18].

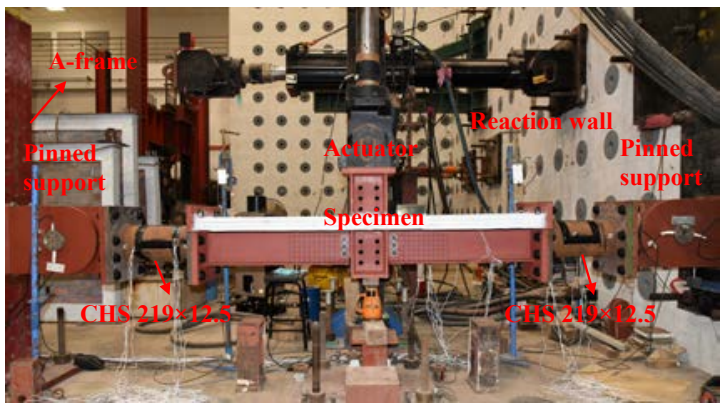

Fig. 1. Front view of quasi-static test set-up.

Fig. 2 shows the impact test set-up. An MTS drop-weight test machine was used to apply impact loads in the test programme. The basic drop-weight of the hammer system was $530 \mathrm{~kg}$ including a load cell system $(60 \mathrm{~kg})$. The dropweight could be increased to $830 \mathrm{~kg}$ by adding 10 pieces of steel plates each weighing $30 \mathrm{~kg}$. The impact hammer was centred to the axis of the middle column joint. 


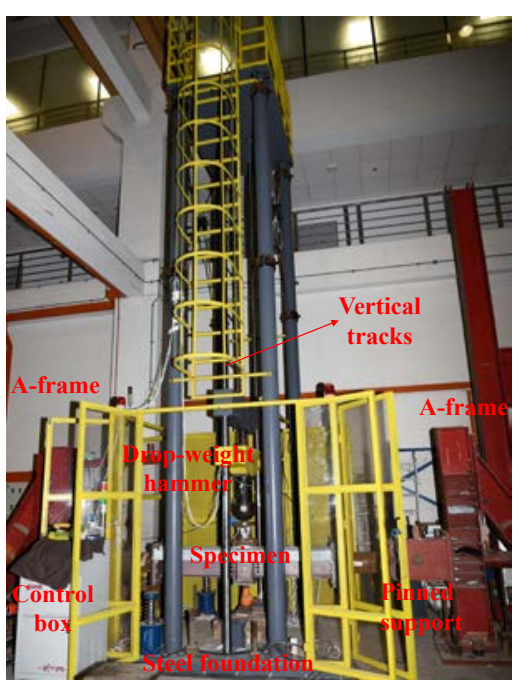

Fig. 2. Front view of impact test set-up.

\subsection{Test results}

Fig. 3 shows the development of static load versus displacement of four typical middle beam-column joints subjected to quasi-static loads. Bare steel joint FP-static was unable to sustain applied load at the initial stage (Fig. 3(a)) due to free rotation of its pin connection. The peak load was obtained at $82.9 \mathrm{~mm}$ and after that, fracture of fin plates occurred so that the applied load decreased dramatically. In contrast, C75FP-M was able to sustain $45 \mathrm{kN}$ of applied load at the initial stage until crushing of concrete occurred due to the composite slab effect (Fig. 3(b)). However, due to greater demand on deformation capacity of the fin plates at the initial stage, fracture of the fin plate in C75FP$\mathrm{M}$ occurred at a smaller displacement than FPstatic (42 mm versus $82.9 \mathrm{~mm}$ ). Since W-static had a stronger beam-column connection compared to FP-static, a greater load (Fig. 3(c)) could be resisted. W-static was more ductile when comparing final displacement at failure (400 $\mathrm{mm}$ versus $300 \mathrm{~mm}$ for FP-static). Due to the composite slab effect, a greater load could be resisted by C75W-M (Fig. 3(d)) at the initial stage. However, due to greater demand on deformation capacity of beam flanges, both the bottom and top beam flanges fractured at a smaller displacement compared with W-static.

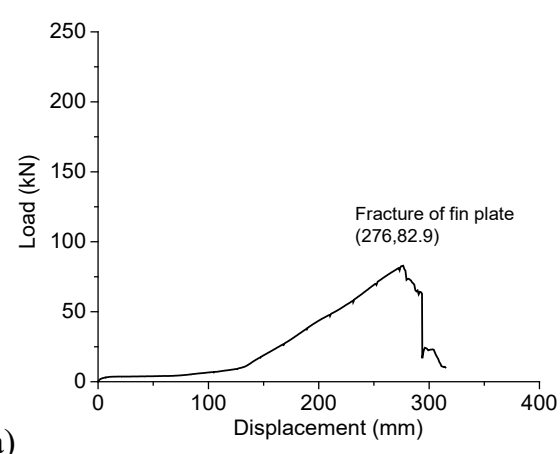

(a)

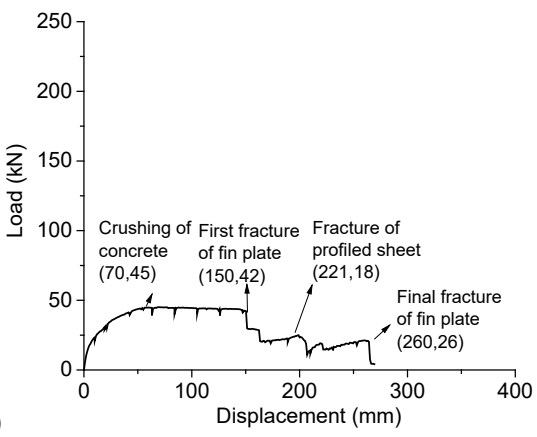

(b)

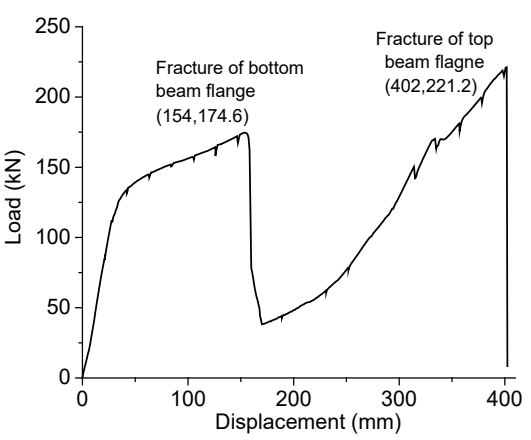

(c)

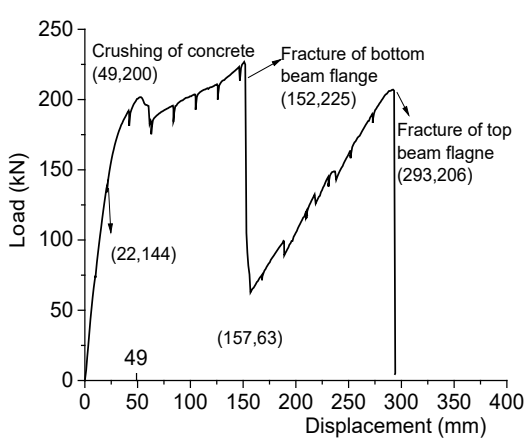

Fig. 3. Load versus displacement curves of typical quasi-static test specimens: (a) FP-static; (b) C75FPM; (c) W-static; (d) C75FP-M

Fig. 4 shows the structural response of four typical beam-column joints subjected to impact loads. Specimen FP6-M530H3 had a 6 mm thick fin plate (bare steel connection) and the impact force development is shown in Fig. 4(a). Each collision consisting of three spikes in Fig. 4(a) represented one visible impact between the hammer head and the specimen. The first spike occurred when the hammer came in contact with the joint. Then the joint rebounded quickly due to horizontal restraint provided by the pinned 
supports. In the test conducted by Grimsmo el al. [19], horizontal restraint was not applied so that only one spike was observed for each collision. C75FP-M530H3 was a composite FP joint and had a greater inertia compared to FP6-M530H3. Therefore, a greater peak impact force was observed (1067.8 kN versus $912 \mathrm{kN}$ for FP6$\mathrm{M} 530 \mathrm{H} 3$ ) as shown in Fig. 4(b) while the velocity in terms of the slope of displacement versus time curve (Fig. 4(c)) was smaller. Specimen W-M830H3 had a welded connection to the column flange and thus it was much stiffer and stronger than fin plate specimen FP6$\mathrm{M} 530 \mathrm{H} 3$. A greater drop-weight of $830 \mathrm{~kg}$ was employed compared to FP6-M530H3. Therefore, a greater peak impact load $(999.1 \mathrm{kN})$ was observed as shown in Fig. 4 (d). A stable period was observed between $15 \mathrm{~ms}$ and $50 \mathrm{~ms}$ for W-M830H3, which was also found in the impact test conducted by Fujikake el al. [20]. A similar phenomenon was observed for $\mathrm{C} 75 \mathrm{~W}$ $\mathrm{M} 770 \mathrm{H} 3$. Due to greater inertia compared to the bare steel joint, C75W-M770H3 had a greater peak impact force $(1188.9 \mathrm{kN}$ versus $999.1 \mathrm{kN}$ for W-M830H3) as shown in Fig. 4(e). Complete fracture of the connection was not observed in the WUF-B joints. The respective residual displacements caused by plastic deformation were $112.8 \mathrm{~mm}$ for $\mathrm{W}-\mathrm{M} 830 \mathrm{H} 3$ and $50.3 \mathrm{~mm}$ for C75W-M770H3 (Fig. 4(f)).

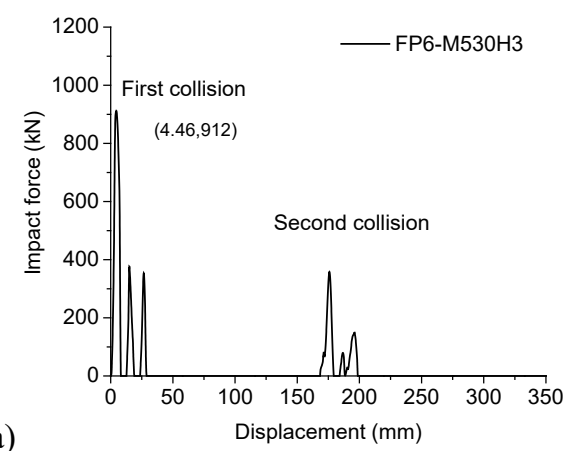

(a)

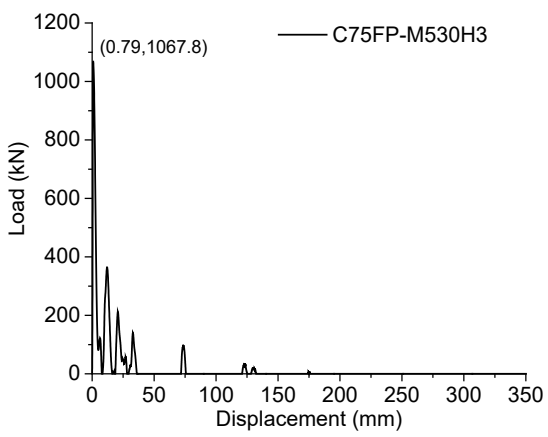

(c)
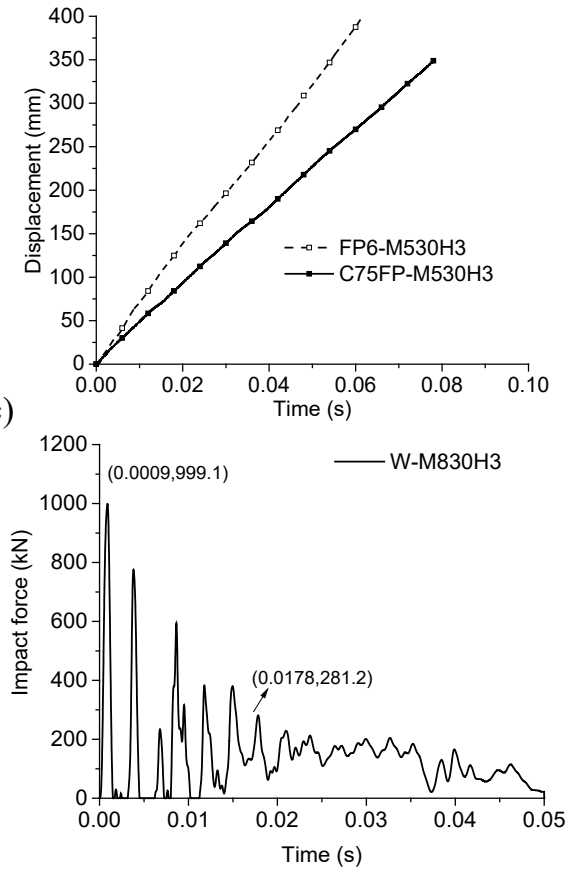

(d)
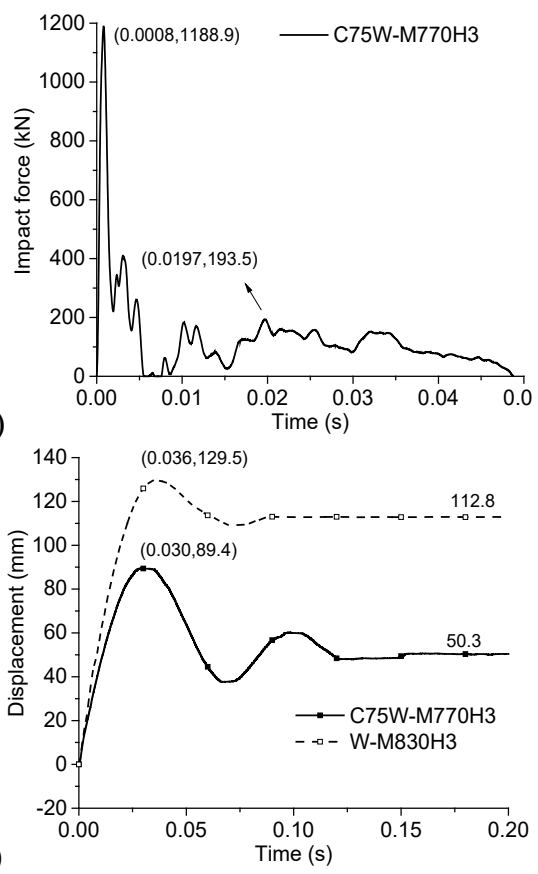

Fig. 4. Structural responses of typical impact test specimens: (a) Impact force development of FP6M530H3; (b) Impact force development of C75FPM530H3; (c) Displacement development of FP specimens; (d) Impact force development of WM830H3; (e) Impact force development of C75WM770H3; (f) Displacement development of WUF-B specimens.

\section{Numerical study}

Component-based models have been proposed for bolted angle and end plate connections subjected to column removal scenarios [21, 22]. In this paper, they are used to simulate beam-column joints with FP and WUF- 
B connections. Nonlinear springs in the component-based models include the concrete slab, reinforcing bar, profiled sheeting, steel beam flange and bolted connection.

\subsection{Concrete slab}

Concrete properties can be obtained from either codified models or concrete material tests. For instance, concrete stress-strain relationship in uniaxial compression and tension can be adopted from the fib Model Code [23]. In this work, the contribution of concrete tension force is neglected.

In the experimental tests, failure of concrete was observed in a region at a distance roughly equal to one beam depth $\left(h_{b}\right)$ from the column flange. Therefore, gauge length $\left(h_{g}\right)$ of the concrete spring is set as the beam depth plus half the column depth, which is calculated from the column centreline. The peak compression force $\left(F_{c m}\right)$ of concrete spring is equal to the tension force provided by the steel components including the beam flange, bolt rows, and profiled sheeting. Therefore, for each connection type, individual concrete spring property must be defined. It should be noted that $F_{c m}$ should not exceed the maximum compressive resistance of the concrete slab, equal to the area of concrete $\left(A_{c}\right)$ multiply by cylinder compressive strength $\left(f_{c m}\right)$.

\subsection{Reinforcing bar}

Under compression, crushing and spalling of concrete surface can accelerate buckling of reinforcing bars, which was observed in the test. Therefore, compressive strength of reinforcing bars may be negligible. A bilinear curve of a tensile spring representing the reinforcing bars based on the yield strength $\sigma_{y}$, ultimate strength $\sigma_{u}$, elastic modulus $E$ and nominal area of the bars is used. Only continuous reinforcing bars are considered while discontinuous bars are ignored. Gauge length $\left(h_{g}\right)$ of the reinforcing bar spring is the same as that of the concrete spring.

\subsection{Profiled sheeting}

Since the thickness of the steel profiled sheeting is $1 \mathrm{~mm}$, local buckling can substantially weaken its compressive resistance. Therefore, profiled sheeting in compression is negligible. Profiled sheeting in tension is simplified as a bilinear curve [21] based on coupon tests.

\subsection{Beam flange}

For fin plate connections, gaps exist between the beam flange and the column flange. The stiffness and resistance of the beam flange and the column flange in compression are much greater than those of a bolt row. Therefore, it is assumed that the stiffness and resistance of the beam flange and the column flange are infinite when the gap between them closes up.

For WUF-B connections, top and bottom beam flanges are welded to the column flange. Beam flange spring can be simplified as a simply-supported column element with a gauge length equal to one beam depth. The column element has the same rectangular cross-section as the beam flange.

\subsection{Bolted connection}

The behaviour of bolted connections in both compression and tension has to be considered.

a) Bolts in bearing between fin plate and beam web

Several methods have been proposed to predict the ultimate strength $R_{n, b r}$ of bolts in bearing and they are included in national design codes such as Eurocode 3 Part 1-8 [13], AISC 360-10 [15] and CSA S16-09 [24]. The equation in Eurocode 3 Part 1-8 [13] gave a more conservative strength prediction compared to the AISC and CSA codes. Therefore, for more accurate predictions of the joint behaviour, the equation in AISC 360-10 is adopted as follows:

$R_{n, b r}=1.5\left(L_{e}-\frac{d_{b}}{2}\right) t \sigma_{u} \leq 3 t d_{b} \sigma_{u}$

where $L_{e}$ is the end distance from the centre of a bolt hole to the edge of the fin plate measured in the direction of load transfer (horizontal direction), $d_{b}$ is the nominal diameter of the bolt, $t$ is the thickness of the plate, and $\sigma_{u}$ is the ultimate strength of the steel plate.

Fin plates may fail in block tearing mode prior to bolt bearing failure when the end distance is not adequate [25]. In this instance, bolt in bearing resistance in Eq. (1) cannot be achieved and block tearing resistance is used instead. Eurocode 3 Part 1-8 [13] provides block tearing resistance as follows:

$R_{n, b s}=\sigma_{u} A_{n t}+(1 / \sqrt{3}) \sigma_{y} A_{n v}$

where $A_{n t}$ is net area subjected to tension and $A_{n v}$ is net area subjected to shear. 
The stiffness of bolt in bearing $k_{i}$ is determined from Eq. (3) proposed by Rex and Easterling [26]:

$k_{i}=\frac{1}{\frac{1}{k_{b r}}+\frac{1}{k_{b}}+\frac{1}{k_{v}}}$

where $k_{b r}, k_{b}$ and $k_{v}$ are the stiffness values of bolt bearing, edge steel plate bending and shearing, respectively. They are specified by Eqs (4) to (6).

$k_{b r}=120 t \sigma_{y} d_{b}^{(4 / 5)}$

$k_{b}=32 E t\left(\frac{L_{e}}{d_{b}}-\frac{1}{2}\right)^{3}$

$k_{v}=(20 / 3) G t\left(\frac{L_{e}}{d_{b}}-\frac{1}{2}\right)$

where $\sigma_{y}$ is the yield strength, $E$ and $G$ are the respective moduli of elasticity and shear of the steel plate.

Rex and Easterling [27] proposed forcedisplacement relationship of bolts in bearing based on experimental tests. The relationship is capable of predicting the behaviour of steel joints with reasonable accuracy [28-31]. Therefore, the method is used to represent the constitutive relationship for bolts in bearing, as expressed in Eq. (7).

$F_{b r}=R_{n . b r}\left[\frac{1.74 \bar{\Delta}}{\left(1+\bar{\Delta}^{0.5}\right)^{2}}-0.009 \bar{\Delta}\right]$

where $F_{b r}$ is the resultant force, $\bar{\Delta}=\frac{\Delta k_{i}}{R_{n, b r}}$ is the normalised displacement, and $\Delta$ is the displacement.

The main difference between the bolt rows in compression and tension arises from the bearing resistance at the bolt holes. In compression, the resistance of bolts in bearing can be calculated from Eq. (8).

$R_{n, b r}=3 t d_{b} \sigma_{u}$

The stiffness of bolt rows in compression can be determined by Eq. (3).

\section{b) Bolts in shear}

When shear failure of bolt shank governs failure mode of bolted connections, properties of bolts in shear should be used.

The ultimate strength of bolts in single shear is determined by Eq. (9).

$R_{n v, b o l t}=0.6 \frac{\pi d_{b}^{2}}{4} \sigma_{u b}$

where $\sigma_{u b}$ is the ultimate strength of the bolt. c) Influence of oversized bolt hole and friction

Typically, an oversized bolt hole is used in construction practice to facilitate the installation of bolts. It can be predicted that the bolt shank moves towards the gap before contacting the steel plate, as shown in Fig. 5. Movement of the bolt shank may vary from 0 to twice the gap distance. In simulations, it can be assumed that the axis of bolt shank is concentric with the centroid of plate holes for simplification.
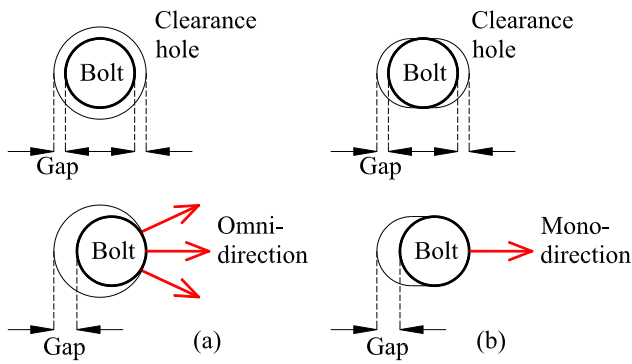

Fig. 5. Direction of bolt movement: (a) Oversized hole; (b) Slotted hole (Taib [28]).

During the movement of bolt shank, only friction force exists and its magnitude depends on the surface treatment of the plate and the bolt type. Friction force $F_{s, R d}$ given by Eurocode 3 Part 1-8 [13] is expressed as follows:

$F_{s, R d}=0.7 k_{s} n \mu \sigma_{u b} A_{s}$

where $k_{s}$ is a coefficient to account for the effect of the type of bolt holes, $n$ is the number of friction surface, $\mu$ is the coefficient of slip, $A_{S}$ is the stressed area of bolt, usually taken as $75 \%$ of bolt gross area calculated using the nominal diameter.

A constant value equal to $F_{S, R d}$ can be assumed as a threshold force before the bolt starts to sustain bearing stress.

d) Failure criteria

Failure of bolted connection is governed by its weakest component. Test results on fin plate connections subjected to catenary action $[29,32]$ indicate two possible failure modes, namely, shear failure of bolts and tear-out failure of steel plates, depending on the relative resistance between the bolts and the steel plates.

In component-based models, deformation capacity of each bolt row is defined in tension and compression respectively. Oosterhoof [31] provided the ultimate deformations of bolt rows in tension. The value is about 0.8 to 1.0 time of end distance. Since there are not sufficient test data on the ultimate deformations of bolt rows, it 
is recommended that $70 \%$ of end distance can be used. For bolt rows in compression, shear failure of bolts is dominant over tear-out failure of fin plates, and the ultimate deformation is around 0.23 times of bolt diameter.

\subsection{Vertical shear}

An elastic spring can be used to model behaviour of joints subjected to shear force. In the vertical direction, bolts function in parallel. Therefore, stiffness of the elastic spring can be assumed to be the stiffness of bolts in bearing $\left(k_{i}\right)$ multiplied by the number of bolts.

\subsection{Strain rate effect}

Material properties of steel and concrete can be affected by high strain rate, which leads to different behaviour of basic components under impact load. To consider the strain rate effect of steel and concrete materials, dynamic increase factors $(D I F \mathrm{~s})$ are used based on previous research studies [23, 33].

For concrete material, $D I F \mathrm{~s}$ at strain rate $\dot{\varepsilon}_{c}$ from the fib Model Code [23] can be adopted.

For steel material, the Cowper and Symonds model is employed as follows:

$D I F=1+\left(\frac{\dot{\varepsilon}}{C}\right)^{\frac{1}{p}}$

where 6844 and 3.91 are adopted for constants $C$ and $p[33] ; \dot{\varepsilon}$ is the strain rate.

Under impact loading scenario, the respective yield and ultimate strengths $\left(\sigma_{y}\right.$ and $\left.\sigma_{u}\right)$ of steel are modified by DIF obtained from Eq. (11).

The relationship between strain rate $\dot{\varepsilon}$ and displacement of each component $\Delta$ can be obtained from Eqs. (12) to (14), which are modified from the method by Stoddart et al. [34, 35].

$\dot{\varepsilon}=\frac{\varepsilon}{\delta_{t}}$

$\delta_{t}=\frac{\Delta}{v}$

$\dot{\varepsilon}=\frac{\varepsilon}{\Delta} v$

where $v$ is the velocity and $\delta_{t}$ is the time to reach displacement $\Delta$.

\subsection{Model validation}

To validate the modelling approach in Section 3.1, finite element (FE) package ABAQUS was chosen and the springs were simulated by CONNECTOR elements [36]. After determination of the spring properties, nonlinear springs were assembled in the beam-column joint. In the component-based model, beam element was used to simulate linear members including the column, beam, shear stud, circular hollow section (CHS) and bracket support. Shell element was used to simulate two dimensional members including the concrete slab and steel profiled sheeting. Rigid elements were used to connect the springs. Boundary conditions and loads were applied based on the test procedure.

Fig. 6(a) shows a comparison of load-versusdisplacement curves from component-based model and experimental tests for specimen FPstatic. Load applied to FP-static could be captured well by the simulation. When incorporating mechanical properties of beam flanges, load applied to W-static could also be captured well by simulations as shown in Fig. 6(b). Composite joints C75FP-M and C75W-M are shown in Figs. 6(c) and (d), respectively. Although the absolute values of applied load from models and test results have slight differences, each failure including fractures of fin plate, profiled sheeting, beam flanges and reinforcing bars could be captured well by the simulations.

Fig. 7(a) compares predicted displacements from the component-based model and the impact test for bare steel joint FP6-M530H3. Good agreement with the test result was achieved by simulations. In comparison, displacement from the component-based model for W-M830H3 (Fig. 7(b)) was slightly greater than that from the test result, indicating either the applied load was greater or stiffness of the model was smaller. The difference was small so that the componentbased model was acceptable. For composite joint C75FP-M530H3 (Fig. 7(c)), displacement from the component-based model was only slightly smaller than that from the test result. Composite joint C75W-M770H3 had welded connections so that it was sufficient to withstand the impact load. Therefore, after attaining the peak displacement, C75W-M770H3 recovered partially as shown in Fig. 7(d). It is clear that good agreement with the test result was achieved although the peak displacement was slightly smaller, probably due to a stronger boundary condition. In the test, the A-frames and connected pinned supports acted as an elastic spring in the horizontal direction but due to gaps, 
the restraint force may be overestimated by the simulation.

(a)
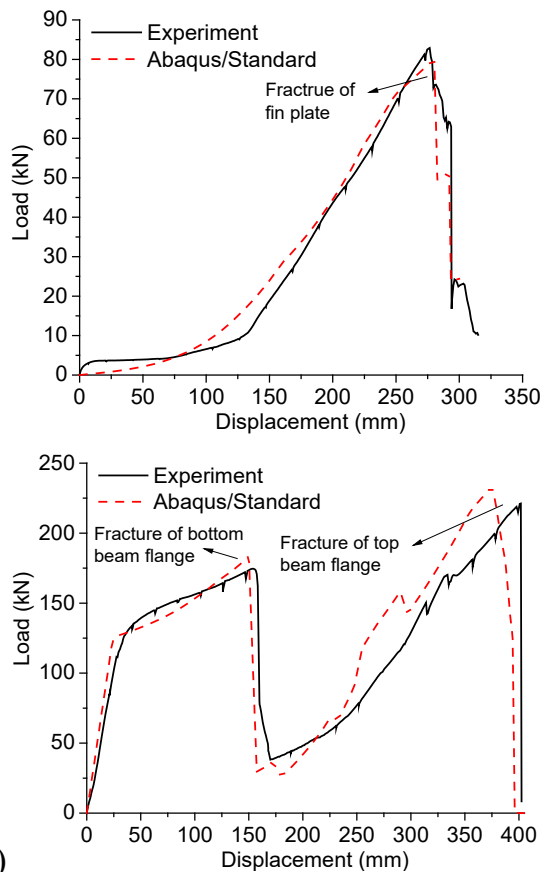

(b)

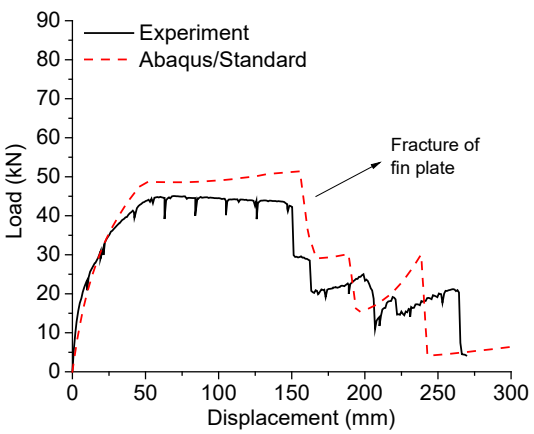

(c)

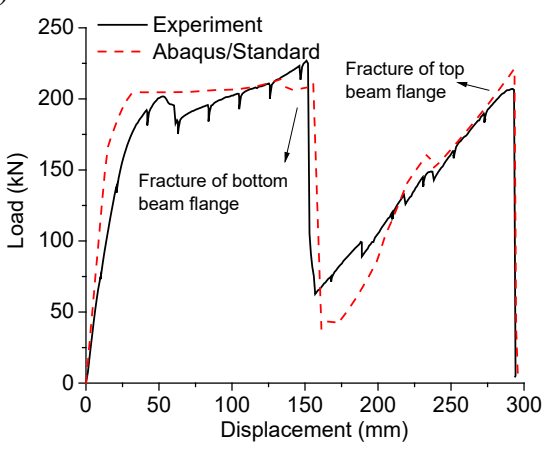

(d)

Fig. 6. Comparison of load-versus-displacement curves from component-based models and test results: (a) FP-static; (b) W-static; (c) C75FP-M; (d) C75W-M

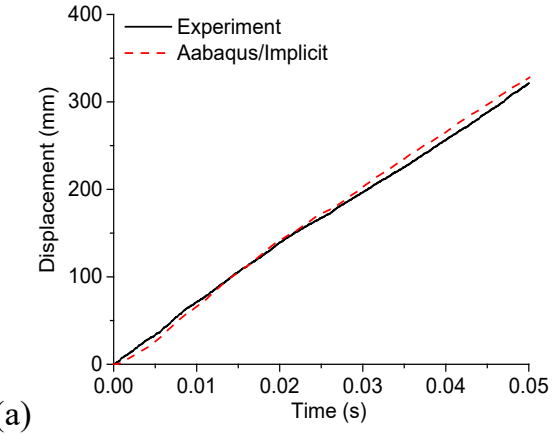

(a)

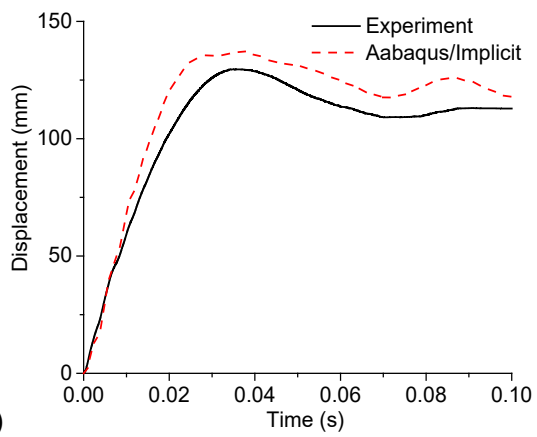

(b)

(c)
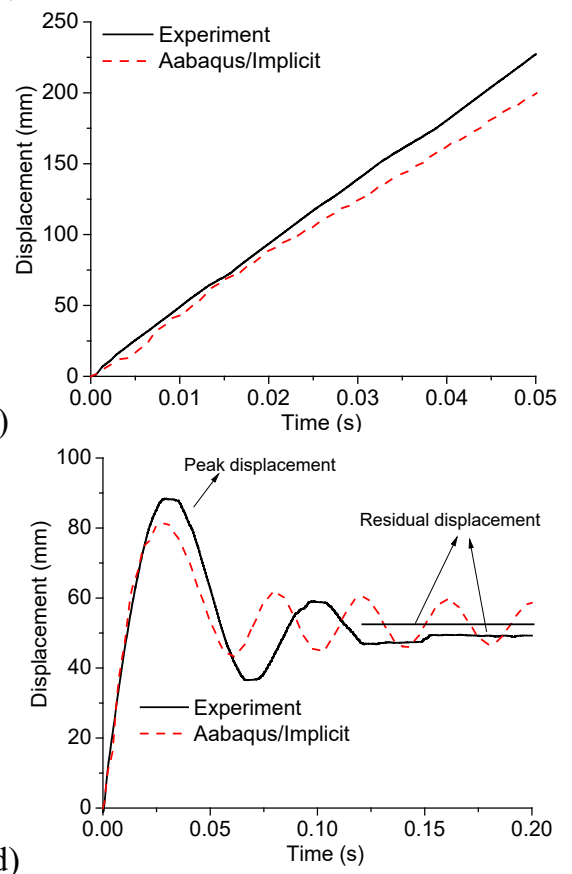

Fig. 7. Comparison of displacement-versus-time curves from component-based models and test results: (a) FP6-M530H3; (b) W-M830H3; (c)

C75FP-M530H3; (d) C75W-M770H3.

\section{Conclusions}

Composite slab effect was beneficial to the initial load-resisting capacity of both FP and WUF-B joints subjected to quasi-static load. However, it induced a decrease of the loadresisting capacity of both types of joints at large deformation stage. Early loss of load-resisting capacity was induced as well due to demand of deformation capacity of beam-column connection at the initial stage. 
Composite slab increased the mass and inertia of beam-column joints so that greater impact forces were observed in both FP and WUF-B joints compared to bare steel joints. Smaller displacements were observed due to the composite slab effect compared to bare steel joints.

A component-based modelling approach was proposed for steel and composite beam-column joints in this study. In the proposed componentbased models, beam-column joints were discretised into individual springs, including the concrete slab, reinforcing bar, profiled sheeting, beam flange and bolted connection. Mechanical property of each spring was determined by material and geometry of individual component. Failure criteria were determined accordingly. Strain rate effect was considered through transforming strain rate to velocity of movement of each spring when applying the models to impact loading scenarios. The models were validated against typical quasi-static joint tests and impact joint tests. Good agreement was obtained.

\section{References}

[1] Thompson SL. Axial, Shear and Moment Interaction of Single Plate" Shear Tab" Connections. U.S.: Milwaukee School of Engineering; 2009.

[2] Driver RG, Oosterhof SA. Performance of Steel Shear Connections under Combined Moment, Shear, and Tension. Structures Congress 2012. Chicago, Illinois, U.S.2012. p. 146-57.

[3] Weigand J, Berman J. Integrity of Steel Single Plate Shear Connections Subjected to Simulated Column Removal. Journal of Structural Engineering. 2014;140:1-12.

[4] Cortés G, Liu J. Behavior of conventional and enhanced gravity connections subjected to column loss. Journal of Constructional Steel Research. 2017; 133:475-84.

[5] Jamshidi A, Driver RG. Full-Scale Tests on Shear Connections of Composite Beams Under a Column Removal Scenario. Structures Congress 2014. Boston, Massachusetts, U.S.2014. p. 931-42.

[6] Karns JE, Houghton DL, Hall BE, Kim J, Lee K. Blast Testing of Steel Frame Assemblies to Assess the Implications of Connection Behavior on Progressive Collapse. Structures Congress 20062006. p. 1-10.

[7] Karns JE, Houghton DL, Hong J-K, Kim J. Behavior of Varied Steel Frame Connection Types Subjected to Air Blast, Debris Impact, and/or PostBlast Progressive Collapse Load Conditions. Structures Congress 2009. Austin, Texas, U.S.2009. p. 1-10.
[8] Sadek F, Main J, Lew H, Bao Y. Testing and Analysis of Steel and Concrete Beam-Column Assemblies under a Column Removal Scenario. Journal of Structural Engineering. 2011;137:881-92. [9] Sadek F, Main J, Lew H, El-Tawil S. Performance of Steel Moment Connections under a Column Removal Scenario. II: Analysis. Journal of Structural Engineering. 2013;139:108-19.

[10] Lew H, Main J, Robert S, Sadek F, Chiarito V. Performance of Steel Moment Connections under a Column Removal Scenario. I: Experiments. Journal of Structural Engineering. 2013;139:98-107.

[11] Li L, Wang W, Chen Y, Lu Y. Experimental investigation of beam-to-tubular column moment connections under column removal scenario. Journal of Constructional Steel Research. 2013;88:244-55.

[12] Li L, Wang W, Chen Y, Lu Y. Effect of beam web bolt arrangement on catenary behaviour of moment connections. Journal of Constructional Steel Research. 2015;104:22-36.

[13] BSI. Eurocode 3: Design of steel structuresPart 1-8: Design of joints. BS EN 1993-1-8. London, U.K.: British Standards Institution; 2005.

[14] BSI. Eurocode 4: Design of composite steel and concrete structures-Part 1-1: General rules and rules for buildings. BS EN 1994-1-1. London, U.K.: British Standards Institution; 2004.

[15] AISC. Specification for Structural Steel Buildings. ANSI/AISC 360-10. Chicago, Illinois., U.S.: American Institute of Steel Construction; 2010. [16] AISC. Steel Conctruction Manual. AISC 32511. Chicago, Illinois., U.S.: American Institute of Steel Construction; 2011.

[17] FEMA. Recommended seismic design criteria for new steel moment frame buildings. FEMA 350. Washington D. C., U.S.: Federal Emergency Management Agency; 2000.

[18] Yang B, Tan KH. Experimental tests of different types of bolted steel beam-column joints under a central-column-removal scenario. Engineering Structures. 2013a;54:112-30.

[19] Grimsmo EL, Clausen AH, Langseth M, Aalberg A. An experimental study of static and dynamic behaviour of bolted end-plate joints of steel. International Journal of Impact Engineering. 2015;85:132-45.

[20] Fujikake K, Li B, Soeun S. Impact response of reinforced concrete beam and its analytical evaluation. Journal of structural engineering. 2009;135:938-50.

[21] Yang B, Tan KH, Xiong G. Behaviour of composite beam-column joints under a middlecolumn-removal scenario: Component-based modelling. Journal of Constructional Steel Research. 2015;104:137-54.

[22] Kang S-B, Tan KH, Liu H-Y, Zhou X-H, Yang B. Effect of boundary conditions on the behaviour of composite frames against progressive collapse. Journal of Constructional Steel Research. 2017;138:150-67. 
[23] fib. Model Code for Concrete Structures 2010. Berlin, Germany: John Wiley \& Sons; 2013.

[24] CSA. Design of steel structures. CSA S16-09. Ontario, Canada L4W 5N6: Canadian Standards Association; 2009.

[25] Može P, Beg D. A complete study of bearing stress in single bolt connections. Journal of Constructional Steel Research. 2014;95:126-40.

[26] Rex CO, Easterling WS. Behavior and modeling of a single plate bearing on a single bolt. Blacksburg, V.A., U.S.: Virginia Polytechnic Institute and State University; 1996.

[27] Rex C, Easterling W. Behavior and Modeling of a Bolt Bearing on a Single Plate. Journal of Structural Engineering. 2003;129:792-800.

[28] Taib M. The Performance of Steel Framed Structures with Fin-plate Connections in Fire. U.K.: University of Sheffield; 2012.

[29] Weigand JM. The Integrity of Steel Gravity Framing System Connections Subjected to Column Removal Loading [Ph.D.]. U.S.: University of Washington; 2014
[30] Koduru S, Driver R. Generalized ComponentBased Model for Shear Tab Connections. Journal of Structural Engineering. 2014;140:1-10.

[31] Oosterhof SA, Driver RG. Shear connection modelling for column removal analysis. Journal of Constructional Steel Research. 2016;117:227-42.

[32] Yang B. The Behavior of Steel and Composite strctures under a Middle-Column-Removal Scenario [Ph.D.]. Singapore: Nanyang Technological University; 2013.

[33] Abramowicz W, Jones N. Dynamic axial crushing of square tubes. International Journal of Impact Engineering. 1984;2:179-208.

[34] Stoddart EP, Byfield MP, Davison JB, Tyas A. Strain rate dependent component based connection modelling for use in non-linear dynamic progressive collapse analysis. Engineering Structures. 2013;55:35-43.

[35] Stoddart E, Byfield M, Tyas A. Blast Modeling of Steel Frames with Simple Connections. Journal of Structural Engineering. 2014;140:1-11.

[36] Dassault Systèmes. ABAQUS 6.11 analysis user's manual2011. 